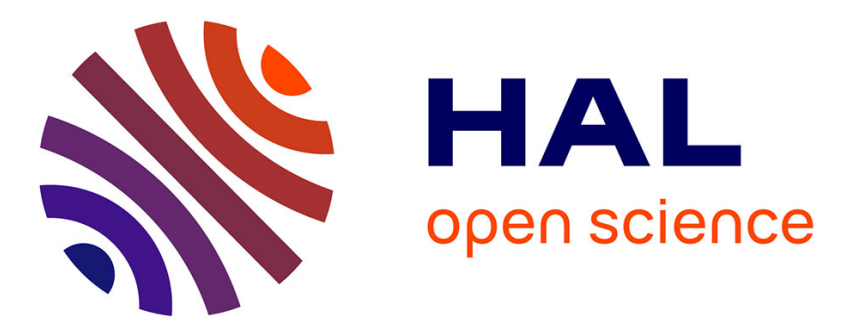

\title{
Raman study of the substrate influence on graphene synthesis using a solid carbon source via rapid thermal annealing
}

Yannick Bleu, Florent Bourquard, A.-S. Loir, Vincent Barnier, Florence

Garrelie, Christophe Donnet

\section{To cite this version:}

Yannick Bleu, Florent Bourquard, A.-S. Loir, Vincent Barnier, Florence Garrelie, et al.. Raman study of the substrate influence on graphene synthesis using a solid carbon source via rapid thermal annealing. Journal of Raman Spectroscopy, In press, 50, pp.1630-1641. 10.1002/jrs.5683 . hal02195906

\section{HAL Id: hal-02195906 \\ https://hal.science/hal-02195906}

Submitted on 26 Jul 2019

HAL is a multi-disciplinary open access archive for the deposit and dissemination of scientific research documents, whether they are published or not. The documents may come from teaching and research institutions in France or abroad, or from public or private research centers.
L'archive ouverte pluridisciplinaire HAL, est destinée au dépôt et à la diffusion de documents scientifiques de niveau recherche, publiés ou non, émanant des établissements d'enseignement et de recherche français ou étrangers, des laboratoires publics ou privés. 


\title{
Raman study of the substrate influence on graphene synthesis using a solid carbon source via rapid thermal annealing
}

\author{
Y. Bleu ${ }^{1}$, F. Bourquard ${ }^{1}$ A.-S. Loir ${ }^{1}$, V. Barnier ${ }^{2}$, F. Garrelie ${ }^{1}$, C. Donnet $^{1}$ \\ (1) Université de Lyon, Université Jean Monnet-Saint-Etienne, CNRS, Institut d'Optique Graduate School, \\ Laboratoire Hubert Curien UMR 5516, F-42023, SAINT-ETIENNE, France \\ (2) Université de Lyon, Mines Saint-Etienne, CNRS, Laboratoire Georges Friedel UMR 5307 CNRS, F-42023 Saint- \\ Etienne, France
}

\begin{abstract}
We report the results of a comparative investigation of graphene films prepared on $\mathrm{Si}(100)$ and fused silica $\left(\mathrm{SiO}_{2}\right)$ combining pulsed laser deposition and rapid thermal annealing using $\mathrm{Ni}$ catalyst. The effect of modifying the substrate and/or growth temperature $\left(600-1000^{\circ} \mathrm{C}\right)$ of graphene synthesis was investigated by Raman micro-spectroscopy mapping. Graphene grown on $\mathrm{Si}(100)$ was multilayered, and various nickel silicide phases had formed underneath, revealing dependence on the growth temperature. Films prepared on $\mathrm{SiO}_{2}$ mainly comprised bi- and tri-layered graphene, with no traces of nickel silicide. Analysis of Raman $\mathrm{D}, \mathrm{G}$, and 2D peak intensities and positions showed that modifying the growth temperature had different effects when a $\mathrm{Si}(100)$ or a $\mathrm{SiO}_{2}$ substrate is used. These findings advance our understanding of how different combinations of substrate and thermal processing parameters affect graphene synthesis from solid carbon source using nickel as a catalyst. This knowledge will enable better control of the properties of graphene film (defects, number of layers, etc.), and will have a high potential impact on the design of graphene-based devices for scientific or industrial applications.
\end{abstract}

Keywords: Graphene, pulsed laser deposition, rapid thermal annealing, nickel silicide, substrate effect. 


\section{Introduction}

Graphene is a remarkable 2D material with a unique combination of mechanical, electronic, optical and thermal properties ${ }^{[1-7]}$.These properties mean graphene could be used in many technological fields including transparent electrodes, field emitters, biosensors, batteries ${ }^{[8-12]}$, to cite but a few examples. Many techniques exist for producing graphene including chemical vapor deposition, chemical reduction of graphene oxide, exfoliation, epitaxial growth on $\mathrm{SiC}$ or metal substrates, and physical vapor deposition methods including pulsed laser deposition (PLD) ${ }^{[13-30]}$. Whatever the synthesis route chosen, many experimental factors affect the graphene nanoarchitecture and properties. However, the influence of using substrates of different natures and compositions - all other parameters being fixed - has rarely been investigated to observe their specific effects on the nature and properties of the synthetized graphene films. In the particular case of PLD, graphene growth is generally achieved using $\mathrm{Si}^{[31-34]}, \mathrm{SiO}_{2}{ }^{[35]}, \mathrm{SiO}_{2} / \mathrm{Si}^{[36]}$ and $\mathrm{Cu}$ foil ${ }^{[37]}$ substrates, with various metallic catalysts $(\mathrm{Cu}, \mathrm{Ni}$, etc.) and thermal processing techniques. Even so, it is still difficult to assess the impact of the substrate on the nature and quality of the graphene films due to changes in the PLD and thermal processing parameters from one publication to another.

A good understanding of the impact of the substrate on the nature and quality of the resulting graphene is vital for potential applications. The objective of this study was thus to synthesize graphene on two different typical substrates, crystallized silicon $\mathrm{Si}(100)$ and amorphous $\mathrm{SiO}_{2}$, using the same deposition and growth process. PLD is a robust way to generate a solid carbon for graphene growth on the two different substrates. A thin Ni catalyst film is then deposited on the top surface by thermal evaporation. Finally, rapid thermal annealing (RTA) is performed in low-vacuum at temperatures between 600 and $1000^{\circ} \mathrm{C}$, inducing few-layer or multilayer graphene formation as is classically reported in the literature using such carbonnickel stacks ${ }^{[38]}$. In this way, the specific effect of the substrate on graphene-based films nanoarchitecture can be assessed, since identical deposition and heating processes are used for both substrates. The films are usually characterized by Raman micro-spectroscopy, a recognized technique for investigating the nanostructure, crystallite size, defects and number of layers in graphene materials ${ }^{[39-58]}$. Specifically, surface mapping of the Raman signal is performed to accurately assess the homogeneity of the samples at the micrometric scale. Raman spectra of carbon materials typically exhibit numerous contributions, among which three are of major significance for studying graphene: the so-called $D, G$ and $2 D$ peaks appearing respectively at shifts around $1350 \mathrm{~cm}^{-1}, 1580 \mathrm{~cm}^{-1}$ and $2700 \mathrm{~cm}^{-1}$. Their shapes, 
intensities, and positions provide considerable information about the graphene films, including domain sizes, defects, number of layers, and stress. The sharp G peak corresponds to the in-plane vibration mode of $\mathrm{sp}^{2}$ hybridized carbon atoms. The $\mathrm{D}$ peak corresponds to the breathing of aromatic rings in the graphene lattice, and only appears in the presence of defects. The 2D peak is the result of a two-phonon lattice vibration process in graphene, observed even without any disorder or defects. The study of this last feature is probably one of the most important in characterizing the graphene-like quality of a film. The $2 \mathrm{D}$ on $\mathrm{G}$ peak intensity ratio $\left(\mathrm{I}_{2 \mathrm{D}} / \mathrm{I}_{\mathrm{G}}\right)$, the full width at half the maximum $2 \mathrm{D}$ peak (FWHM(2D)) and, to a lesser extent, the position of the $2 \mathrm{D}$ peak, make it possible to determine the number of layers (within 1-5) of few-layer graphene with a relatively good degree of accuracy. Given the huge amount of scientific synthesis and use of graphene, and to discuss the quality of samples produced for this study, we reviewed 50 references in the literature (see also Supplementary S0). Our focus was on associating $\mathrm{I}_{2 \mathrm{D}} / \mathrm{I}_{\mathrm{G}}$ and $\mathrm{FWHM}(2 \mathrm{D})$ data with the number of layers in few-layer graphene, for the purpose of quantification. The resulting correlations are listed in Table 1. When the $I_{2 D} / I_{G}$ ratio is below 0.6 , it is generally accepted that the graphene film contains more than 4 layers, with a near-certainty of more than 5 layers when $\mathrm{I}_{2 \mathrm{D}} / \mathrm{I}_{\mathrm{G}}$ is below 0.4. Additionally, the $2 \mathrm{D}$ peak position upshifts to $50 \mathrm{~cm}^{-1}$ when the number of layers increases from 1 to 5. For more than 4-5 layers, the FWHM(2D) cannot be used to quantify the number of layers, and the 2D signature becomes similar to that of graphite.

\begin{tabular}{lll}
\hline & $\mathbf{I}_{2 \mathbf{D}} / \mathbf{I}_{\mathbf{G}}$ & FWHM(2D) \\
\hline Monolayer & $>1.3$ & $24-50$ \\
Bilayer & $0.7-2.2$ & $38-65$ \\
Trilayer & $0.6-0.7$ & $55-85$ \\
$4-5$ Layers & $0.4-0.6$ & $/ /$ \\
Multilayers (5-10) & $<0.4$ & $/ /$ \\
\hline
\end{tabular}

Table 1: Summary of $\mathrm{I}_{2 \mathrm{D}} / \mathrm{I}_{\mathrm{G}}$ ratio and $\mathrm{FWHM}(2 \mathrm{D})$ for different graphene layers, based on 50 references (see Supplementary S0).

Studying the D peak is a good way to evaluate the defective nature of a graphene sample structure. Its intensity, compared to that of the G peak, can be used to investigate the quality of graphene. By studying the $\mathrm{D}$ to $\mathrm{G}$ peak intensity ratio $\left(\mathrm{I}_{\mathrm{D}} / \mathrm{I}_{\mathrm{G}}\right)$, the crystallite size in the graphene material can be estimated using the Tuinstra-Koenig relation: 


$$
\boldsymbol{L}_{\boldsymbol{a}}(\mathrm{nm})=\left(2,4 \times 10^{-10}\right) \lambda^{4}\left(\frac{\boldsymbol{I}_{\boldsymbol{D}}}{\boldsymbol{I}_{G}}\right)^{-1}
$$

where $\lambda$ is the laser wavelength in nanometers, and $L_{a}$ is the average size of the crystallites.

This literature survey is used in section 4 to discuss the Raman results described in section 3 characterizing the graphene films obtained with various RTA parameters on both $\mathrm{Si}(100)$ and $\mathrm{SiO}_{2}$ substrates.

\section{Experimental}

\subsection{Sample preparation}

The steps used to prepare the samples are shown in Fig. 1. First, the $\mathrm{Si}(100)$ and $\mathrm{SiO}_{2}$ substrates were cleaned ultrasonically (successively in acetone, ethanol and deionized water baths). Second, amorphous carbon (a-C) was deposited by PLD in a vacuum at a base pressure of $10^{-4} \mathrm{~Pa}$. The PLD targets were high purity (99.9995\%) micro-crystalline graphite disks. Ablation was performed using an excimer $\mathrm{KrF}$ laser (248 nm wavelength, $20 \mathrm{~ns}$ pulse duration, $10 \mathrm{~Hz}$ repetition rate) at room temperature, focused with a $50 \mathrm{~cm}$ lens producing a $2.2 \mathrm{~mm}^{2}$ semi-Gaussian elliptic spot. This gives an average energy density (fluence) of the laser beam at $4.5 \mathrm{~J} / \mathrm{cm}^{2}$. The ablation time was adjusted to keep an amorphous (a-C) film thickness of $10 \mathrm{~nm}$, deposition speed having been estimated at $10 \mathrm{~nm} / \mathrm{min}$ by profilometry. The substrates were mounted on a sample holder placed at a distance of $40 \mathrm{~mm}$ from the graphite target. A $60 \mathrm{~nm}$ thick nickel film was subsequently deposited by thermal evaporation on the top of the a-C/Si or a-C/SiO 2 substrate in a vacuum chamber pumped at a base pressure of $10^{-4} \mathrm{~Pa}$. High purity $(99.99 \%) \mathrm{Ni}$ was heated in a tungsten nacelle and evaporated towards the substrates. The last step was rapid thermal annealing. To this end, the Ni/a-C/Si or Ni/a$\mathrm{C} / \mathrm{SiO}_{2}$ samples were placed in a $\mathrm{SiC}$ susceptor in an RTA oven pumped at $5 \mathrm{~Pa}$. The heating rate, controlled by PID, was set at $15^{\circ} \mathrm{C} / \mathrm{s}$ as measured by a pyrometer located on the back of the susceptor. Cooling from high temperature was set at a maximum of $1{ }^{\circ} \mathrm{C} / \mathrm{s}$ or natural cooling (whichever is slower). Different maximum temperatures ranging from 600 to $1000^{\circ} \mathrm{C}$, are reached and held for 10 minutes. Table 2 lists the resulting samples with their label and synthesis conditions. 


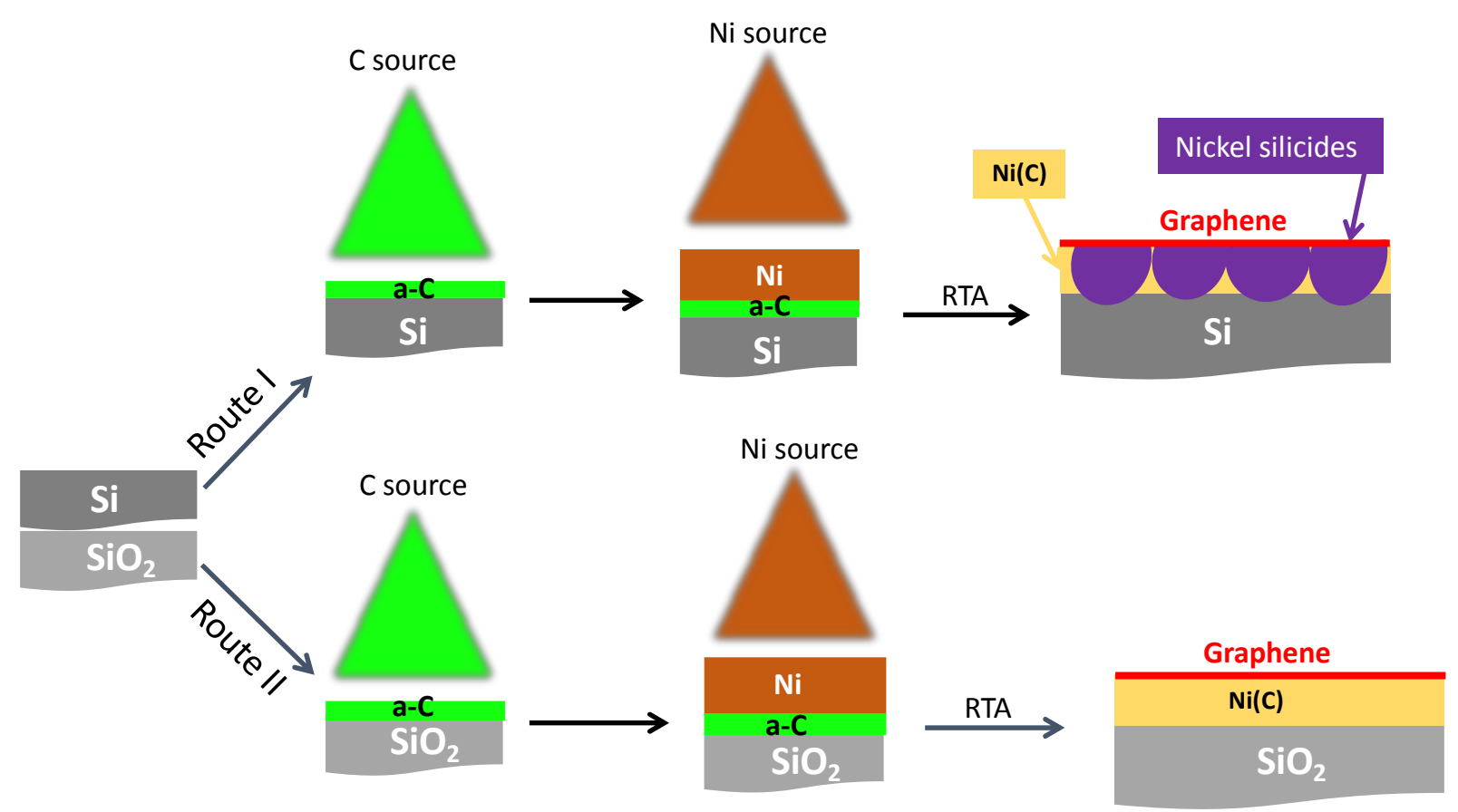

Fig. 1: Synthesis route of graphene films obtained by combining pulsed laser deposition and rapid thermal annealing on both $\mathrm{Si}(100)$ and $\mathrm{SiO}_{2}$ substrates. The formation of nickel silicides with the $\mathrm{Si}(100)$ substrate is detailed in the "results" section.

\subsection{Sample characterization}

Raman spectroscopy is performed using an Aramis Jobin Yvon spectrometer. The excitation wavelength is $442 \mathrm{~nm}$ (He-Cd source) for graphene spectra and $633 \mathrm{~nm}$ (He-Ne source) for nickel silicide spectra, with a spectral resolution around $2 \mathrm{~cm}^{-1}$. The excitation laser beam is focused with a 100x objective, consistent with a laser spot with a diameter $<1 \mu \mathrm{m}$ for both wavelengths, allowing for submicrometric spatial resolution when performing Raman mapping. The laser power was kept below $3 \mathrm{~mW}$ to avoid damaging the film surface. Rectangular mapping was performed on all samples at $442 \mathrm{~nm}$ excitation wavelength. The probed surface was a $20 \times 20 \mu \mathrm{m}^{2}$ square, with a $1 \mu \mathrm{m}$ spatial sampling. This means that over 400 Raman spectra were collected for each sample.

A custom-made algorithm relying on the SciPy python library was then used to extract relevant information on the Raman peaks: intensity, width, position, etc. Most peaks were fitted with Lorentzian functions, except for the G peak which was fitted with a Breit-WignerFano function accounting for its asymmetry compared to a classical Lorentzian profile ${ }^{[60]}$. Later, when computing intensity ratios, we will be referring, as is usually the case in the literature, to peak height (intensity maximum) as opposed to peak area. All peak properties 
discussed later (FWHM, intensity maximum, positions, etc.) were extracted from the properties of the Lorentzian profiles.

\begin{tabular}{|c|c|c|c|}
\hline & Graphene precursor \& substrate & RTA temperature & Sample label \\
\hline \multirow{5}{*}{$\begin{array}{l}\text { Graphene on } \\
\mathrm{Si}(100)\end{array}$} & $\mathrm{Ni}(60 \mathrm{~nm}) / \mathrm{a}-\mathrm{C}(10 \mathrm{~nm}) / \mathrm{Si}(100)$ & $1000^{\circ} \mathrm{C}$ & G-Si-1000 \\
\hline & $\mathrm{Ni}(60 \mathrm{~nm}) / \mathrm{a}-\mathrm{C}(10 \mathrm{~nm}) / \mathrm{Si}(100)$ & $900^{\circ} \mathrm{C}$ & G-Si-900 \\
\hline & $\mathrm{Ni}(60 \mathrm{~nm}) / \mathrm{a}-\mathrm{C}(10 \mathrm{~nm}) / \mathrm{Si}(100)$ & $800^{\circ} \mathrm{C}$ & G-Si-800 \\
\hline & $\mathrm{Ni}(60 \mathrm{~nm}) / \mathrm{a}-\mathrm{C}(10 \mathrm{~nm}) / \mathrm{Si}(100)$ & $700^{\circ} \mathrm{C}$ & G-Si-700 \\
\hline & $\mathrm{Ni}(60 \mathrm{~nm}) / \mathrm{a}-\mathrm{C}(10 \mathrm{~nm}) / \mathrm{Si}(100)$ & $600^{\circ} \mathrm{C}$ & G-Si-600 \\
\hline \multirow{5}{*}{$\begin{array}{l}\text { Graphene on } \\
\mathrm{SiO}_{2}\end{array}$} & $\mathrm{Ni}(60 \mathrm{~nm}) / \mathrm{a}-\mathrm{C}(10 \mathrm{~nm}) / \mathrm{SiO}_{2}$ & $1000^{\circ} \mathrm{C}$ & $\mathrm{G}-\mathrm{SiO}_{2}-1000$ \\
\hline & $\mathrm{Ni}(60 \mathrm{~nm}) / \mathrm{a}-\mathrm{C}(10 \mathrm{~nm}) / \mathrm{SiO}_{2}$ & $900^{\circ} \mathrm{C}$ & $\mathrm{G}-\mathrm{SiO}_{2}-900$ \\
\hline & $\mathrm{Ni}(60 \mathrm{~nm}) / \mathrm{a}-\mathrm{C}(10 \mathrm{~nm}) / \mathrm{SiO}_{2}$ & $\mathbf{8 0 0}^{\circ} \mathrm{C}$ & $\mathrm{G}-\mathrm{SiO}_{2}-800$ \\
\hline & $\mathrm{Ni}(60 \mathrm{~nm}) / \mathrm{a}-\mathrm{C}(10 \mathrm{~nm}) / \mathrm{SiO}_{2}$ & $7^{700^{\circ}} \mathrm{C}$ & $\mathrm{G}-\mathrm{SiO}_{2}-700$ \\
\hline & $\mathrm{Ni}(60 \mathrm{~nm}) / \mathrm{a}-\mathrm{C}(10 \mathrm{~nm}) / \mathrm{SiO}_{2}$ & $600^{\circ} \mathrm{C}$ & $\mathrm{G}-\mathrm{SiO}_{2}-600$ \\
\hline
\end{tabular}

Table 2: The samples and their growth conditions. RTA annealing was performed in a low vacuum at $5 \mathrm{~Pa}$ for $600 \mathrm{~s}$, preceded by a $+15^{\circ} \mathrm{C} / \mathrm{s}$ heating ramp and followed by cooling limited to $-1^{\circ} \mathrm{C} / \mathrm{s}$.

\section{Results}

\subsection{Substrate effects depending on the annealing temperature}

Raman mappings (20 x $20 \mu \mathrm{m}^{2}$, each integrating 400 Raman spectra) were performed on representative areas to highlight the similarities and differences between the graphene grown on $\mathrm{Si}(100)$ and $\mathrm{SiO}_{2}$ substrates at the five growth temperatures. This made it possible to compute mappings_for the following characteristics: $\mathrm{I}_{\mathrm{D}} / \mathrm{I}_{\mathrm{G}}$ and $\mathrm{I}_{2 \mathrm{D}} / \mathrm{I}_{\mathrm{G}}$ intensity ratios, $2 \mathrm{D}$ peak FWHM, as well as D, G, and 2D peak positions. Table 3 lists the mean values of these characteristics for each sample, averaged from each set of 400 recorded spectra. The most relevant mappings are shown and commented below, the others are provided in Supplementary information. 
Fig. 2a and 2b show the Raman mapping of the $\mathrm{I}_{\mathrm{D}} / \mathrm{I}_{\mathrm{G}}$ intensity ratio for samples grown at all temperatures, on $\mathrm{Si}$ and $\mathrm{SiO}_{2}$, respectively. On the $\mathrm{Si}(100)$ substrate, the mean intensity ratio $\mathrm{I}_{\mathrm{D}} / \mathrm{I}_{\mathrm{G}}$ increased with growth temperature from 0.297 to 0.468 . This suggests a decrease in the mean crystallite size from 31 to $20 \mathrm{~nm}$. This effect is shown in the left plot in Fig. 2c. On the $\mathrm{SiO}_{2}$ substrate, the opposite behavior was observed (as shown in the right plot in Fig. 2c): the mean intensity ratio $\mathrm{I}_{\mathrm{D}} / \mathrm{I}_{\mathrm{G}}$ decreased from 0.293 to 0.140 with an increase in the growth temperature. This was associated with an increase of from 31 to $65 \mathrm{~nm}$ in the mean crystallite size. These results suggest that graphene films grown on $\mathrm{SiO}_{2}$ contain fewer defects and larger crystallites than graphene grown on $\mathrm{Si}(100)$.

\begin{tabular}{l|lllll|lllll}
\hline & \multicolumn{4}{c}{ Graphene on $\mathrm{Si}(100)$} & \multicolumn{5}{c}{ Graphene on $\mathrm{SiO}_{2}$} \\
\hline RTA temperature & $600^{\circ} \mathrm{C}$ & $700^{\circ} \mathrm{C}$ & $800^{\circ} \mathrm{C}$ & $900^{\circ} \mathrm{C}$ & $1000^{\circ} \mathrm{C}$ & $600^{\circ} \mathrm{C}$ & $700^{\circ} \mathrm{C}$ & $800^{\circ} \mathrm{C}$ & $900^{\circ} \mathrm{C}$ & $1000^{\circ} \mathrm{C}$ \\
\hline I $_{\mathrm{D}} / \mathrm{I} G$ & 0.297 & 0.317 & 0.346 & 0.462 & 0.468 & 0.293 & 0.269 & 0.271 & 0.174 & 0.140 \\
$\mathrm{La}(\mathrm{nm})$ & 31 & 29 & 26 & 20 & 20 & 31 & 34 & 34 & 53 & 65 \\
$\mathrm{I}_{2 \mathrm{D}} / \mathrm{I}$ & 0.438 & 0.477 & 0.403 & 0.427 & 0.342 & 0.412 & 0.420 & 0.489 & 0.706 & 0.721 \\
2D position & 2742 & 2739 & 2738 & 2745 & 2754 & 2743 & 2741 & 2737 & 2733 & 2732 \\
$2 \mathrm{D}$ FWHM & 111 & 109 & 108 & 112 & 120 & 108 & 109 & 107 & 87 & 77 \\
$\mathrm{G}$ position & 1577 & 1576 & 1576 & 1584 & 1583 & 1580 & 1579 & 1576 & 1574 & 1573 \\
D position & 1367 & 1365 & 1366 & 1374 & 1373 & 1373 & 1374 & 1367 & 1361 & 1360 \\
\hline
\end{tabular}

Table 3: Mean values of the Raman characteristics resulting from the 400 Raman spectra performed on representative areas of the graphene films and presented as Raman mappings in the proof and in Supplementary information.

Fig. 3a and 3b show Raman mappings of the $I_{2 D} / I_{G}$ intensity ratio for graphene grown at all annealing temperatures, on $\mathrm{Si}(100)$ and $\mathrm{SiO}_{2}$, respectively. On the $\mathrm{Si}(100)$ substrate, the mean $\mathrm{I}_{2 \mathrm{D}} / \mathrm{I}_{\mathrm{G}}$ ratio globally decreased (albeit non-monotonically) with temperature, from 0.477 to 0.342 (as seen in Fig. 3c), whereas the mean FWHM(2D) increased slightly from 111 to $120 \mathrm{~cm}^{-1}$ (see Supplementary Fig. S1). This suggests that the number of graphene layers increases with an increasing growth temperature. The opposite behavior was observed on $\mathrm{SiO}_{2}$ substrates, where the number of graphene layers decreased with an increase in the growth temperature from $600^{\circ} \mathrm{C}$ to $1000^{\circ} \mathrm{C}$. As can be seen in Fig. 3c (right plot), the mean $\mathrm{I}_{2 \mathrm{D}} / \mathrm{I}_{\mathrm{G}}$ intensity ratio increased from 0.412 to 0.721 and the $\mathrm{FWHM}(2 \mathrm{D})$ mean value decreased from 108 to $77 \mathrm{~cm}^{-1}$ (see Supplementary S1) with growth temperature. These results suggest that growth on $\mathrm{SiO}_{2}$ substrates produces graphene films with fewer layers than growth on $\operatorname{Si}(100)$. 
(a) Graphene on $\mathrm{Si}(\mathbf{1 0 0})$
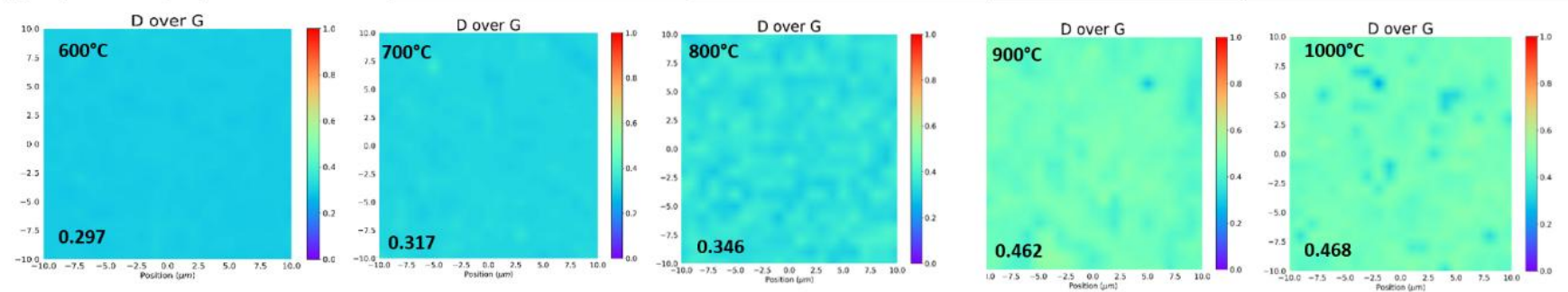

(b) Graphene on $\mathrm{SiO}_{2}$
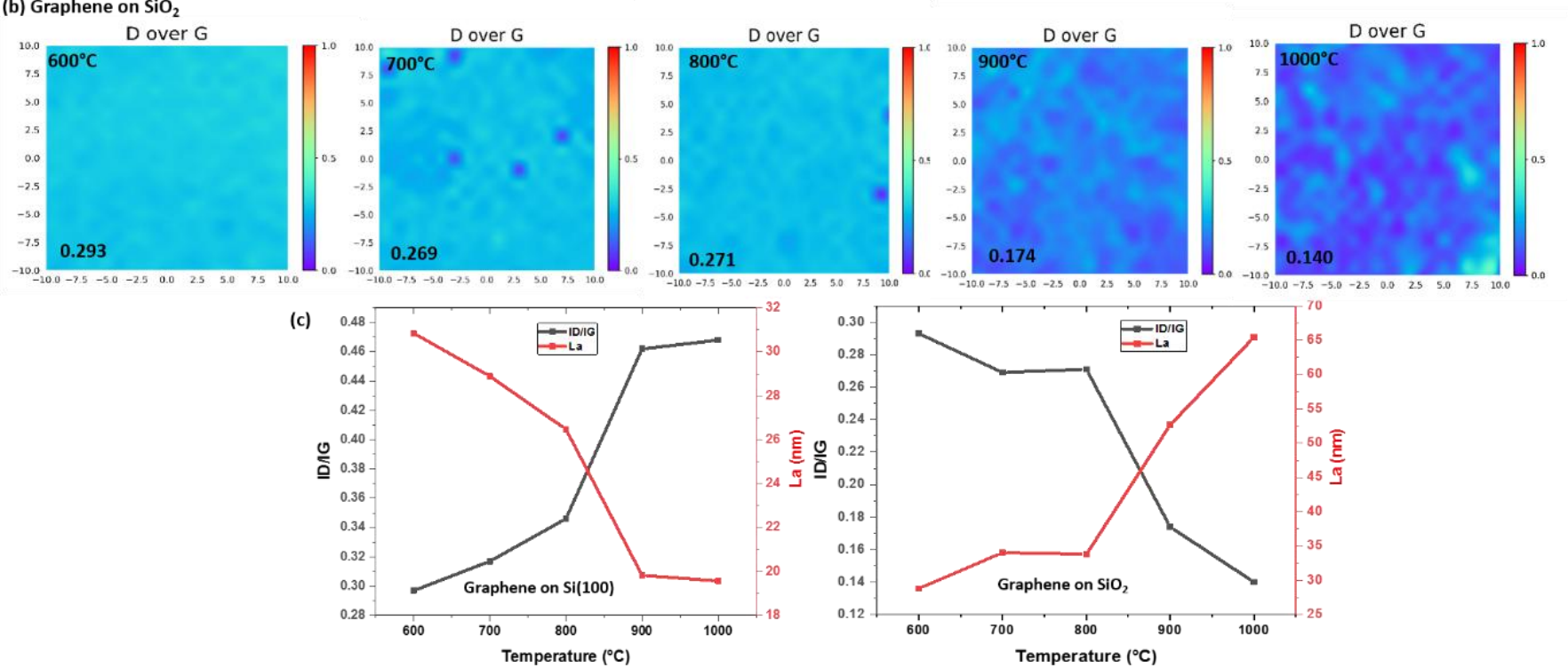

Fig. 2: (a) $\mathrm{I}_{\mathrm{D}} / \mathrm{I}_{\mathrm{G}}$ Raman mapping of as-grown graphene at temperatures ranging from $600-1000^{\circ} \mathrm{C}$ on Si (100) with their mean values, (b) $\mathrm{I}_{\mathrm{D}} / \mathrm{I}_{\mathrm{G}}$ Raman mapping of as-grown graphene at temperatures ranging from $600-1000^{\circ} \mathrm{C}$ on $\mathrm{SiO}_{2}$ with their mean values, (c) Plots showing dependence on growth temperature as a function of mean $\mathrm{I}_{\mathrm{D}} / \mathrm{I}_{\mathrm{G}}$ ratio and crystallite size $\left(\mathrm{L}_{\mathrm{a}}\right)$ : right plot, graphene on $\mathrm{Si}(100)$, left plot, graphene on $\mathrm{SiO}_{2}$.

(a) Graphene on $\mathrm{Si}(100)$
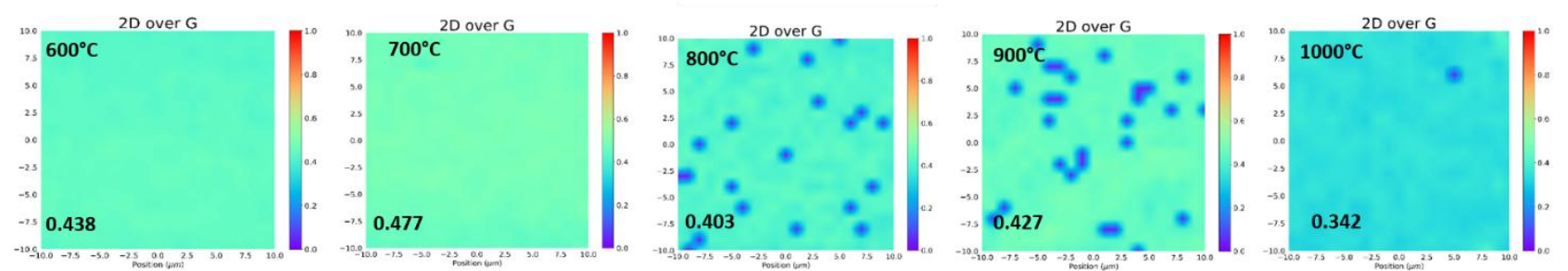

(b) Graphene on $\mathrm{SiO}_{2}$
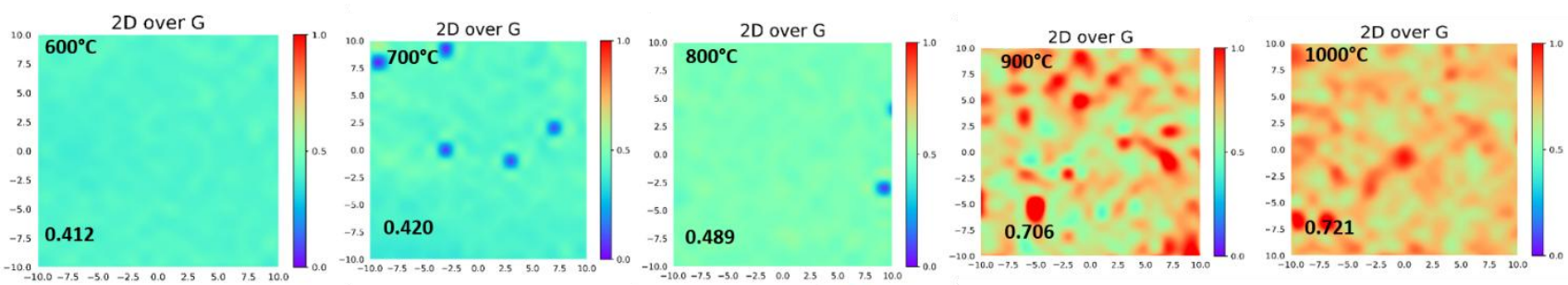

(c)

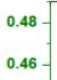


Fig. 3: (a) $I_{2 D} / I_{G}$ Raman mapping_of as-grown graphene at temperatures ranging from $600-1000^{\circ} \mathrm{C}$ on $\mathrm{Si}$ (100) with their mean values, (b) $\mathrm{I}_{2 \mathrm{D}} / \mathrm{I}_{\mathrm{G}}$ Raman mapping of as-grown graphene at temperatures ranging from $600-1000^{\circ} \mathrm{C}$ on $\mathrm{SiO}_{2}$ with their mean values, (c) Plot of growth temperature dependency as a function of the $\mathrm{I}_{2 \mathrm{D}} / \mathrm{I}_{\mathrm{G}}$ ratio and the $\mathrm{FWHM}(2 \mathrm{D})$ : right plot, graphene on Si (100), left plot, graphene on $\mathrm{SiO}_{2}$.

Fig. 4 shows typical Raman spectra extracted from the mapping of each of the samples detailed in Table 2. The abovementioned and commented D, G, and 2D peaks are clearly visible, as are other minor peaks: D+D', near $2450 \mathrm{~cm}^{-1}, \mathrm{D}+\mathrm{G}$ near $2950 \mathrm{~cm}^{-1}$ and 2D' near $3250 \mathrm{~cm}^{-1}$, all already observed in some graphene films. The D + D" and 2D' peaks are, like the $\mathrm{G}$ and $2 \mathrm{D}$ peaks, common features in most graphene samples. They emerge, like the 2D peak, as a combination of two phonon modes individually associated with defects (D' and D") allowing so-called breathing of aromatic rings in carbon materials. The combination of those resonances can appear without defects as the two phonons can verify momentum conservation provided they have opposite wavevectors. In the case of the $\mathrm{D}+\mathrm{G}$ peak, also sometimes labelled D + D', the excitation mechanisms are somewhat unclear but they also appear in defective graphene-like material ${ }^{[61,62]}$. The insert in Fig.4b shows the deconvolution of the 2D peak from a spectrum from the graphene film obtained at $1000^{\circ} \mathrm{C}$ on $\mathrm{SiO}_{2}$. The $2 \mathrm{D}$ peak is deconvoluted into four components each with a FWHM of $28 \mathrm{~cm}^{-1}$. According to Malard et $a{ }^{[40]}$, this is the fingerprint of bilayer graphene. It is worth mentioning that some of the spectra extracted from the mapping of this sample had a substantially larger 2D peak, which were deconvoluted into 6 components (with a FWHM of $28 \mathrm{~cm}^{-1}$ ), which is consistent with trilayer graphene.
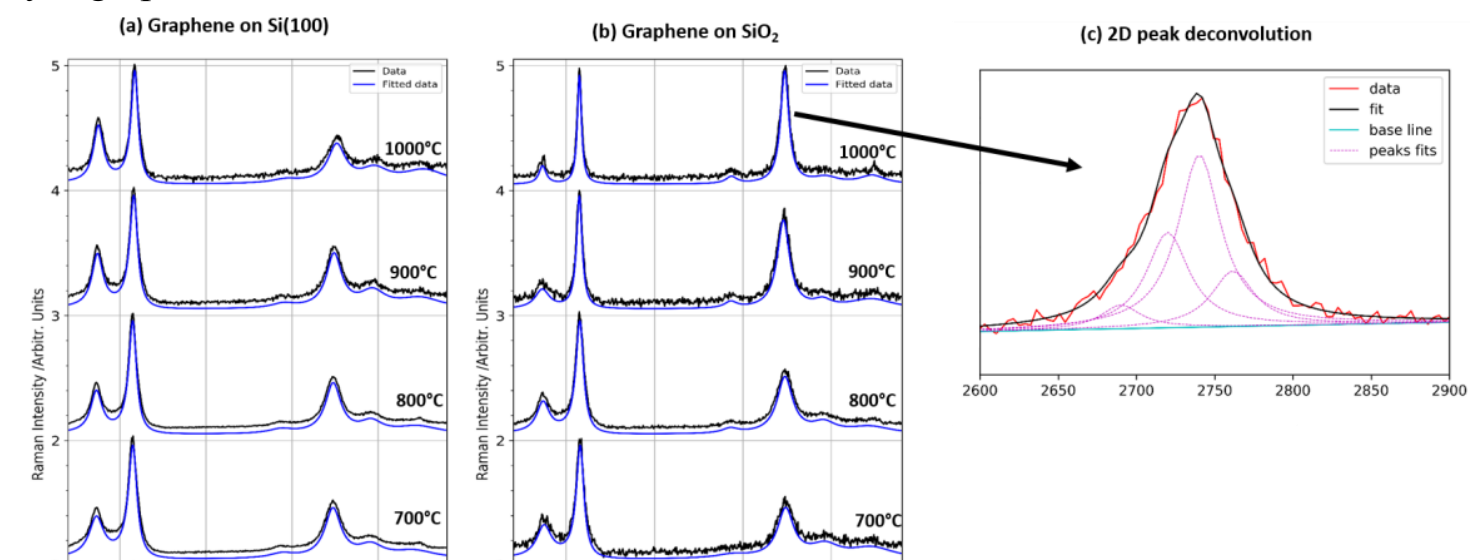
Fig. 4: Typical experimental (black) and fitted (blue) Raman spectra of graphene films grown at temperatures ranging from $600-1000^{\circ} \mathrm{C}$ : (a) on $\mathrm{Si}(100)$, (b) on $\mathrm{SiO}_{2}$ (the red insert corresponds to the deconvolution of $2 \mathrm{D}$ peak of the spectrum of graphene at $1000^{\circ} \mathrm{C}$ on $\mathrm{SiO}_{2}$ ).

\subsection{Identification of nickel silicide phases when using $\operatorname{Si}(100)$ substrates}

To understand the rather different impacts of increasing the annealing temperature on the growth of graphene when using $\mathrm{Si}(100)$ or $\mathrm{SiO}_{2}$ substrates, the reactivity of the Ni catalyst layer with the substrate can be studied. Indeed, diffusion of $\mathrm{Ni}$ atoms into $\mathrm{Si}^{[33]}$ and $\mathrm{SiC}^{[63,64]}$ substrates during annealing, and the concomitant formation of nickel silicide phases have already been reported. This can influence the carbon diffusion process through the Ni catalyst as well as the nature of the resulting graphene film (number of layers, defects, etc.). In this study, the nickel silicide formation using $\mathrm{Si}(100)$ substrate was studied by Raman spectroscopy in the 100 to $500 \mathrm{~cm}^{-1}$ shift range, with a laser excitation at $633 \mathrm{~nm}$, as shown in Fig. 5. The G-Si-600 sample (annealed at $600^{\circ} \mathrm{C}$ ) exhibited no Raman peaks in this spectral region, suggesting that no nickel silicide is present. This could explain the small number of defects in the sample compared with the other samples synthesized at higher temperatures. In addition, the $\mathrm{I}_{\mathrm{D}} / \mathrm{I}_{\mathrm{G}}$ mean ratio $(0.297)$ of the G-Si-600 sample was quite close to the one (0.293) of $\mathrm{G}_{-} \mathrm{SiO}_{2}-600$ (as other Raman characteristics, Table 2), also annealed at $600^{\circ} \mathrm{C}$, suggesting that at this rather low temperature, both graphene films are very similar whatever the nature of the substrate.

At higher annealing temperatures, the evolution of the Raman response differed greatly in the two substrates, which can be correlated with the formation of nickel silicide on the $\mathrm{Si}(100)$ substrate. According to Raman spectral data in the literature ${ }^{[65-69]}, \mathrm{Ni}_{2} \mathrm{Si}, \mathrm{NiSi}$ and $\mathrm{NiSi}_{2}$ nickel silicide phases exhibit peaks at 100 and $140 \mathrm{~cm}^{-1}, 190$ and $215 \mathrm{~cm}^{-1}$ and 230, 295, 320, and $370 \mathrm{~cm}^{-1}$, respectively. In the present study, low wavenumber peaks related to $\mathrm{Ni}_{2} \mathrm{Si}$ were 
never observed whatever the annealing temperature. Bhaskaran et al. ${ }^{[69]}$ observed significant background noise in the spectra in this region, and concluded that the presence of the $\mathrm{Ni}_{2} \mathrm{Si}$ phase, formed by thermal processing of a $\mathrm{Ni}$ thin film on a silicon substrate, could not be confirmed.

A peak near $120 \mathrm{~cm}^{-1}$ (within the 117 and $123 \mathrm{~cm}^{-1}$ range) was observed at all temperatures, except surprisingly at $700^{\circ} \mathrm{C}$. Huong et al. ${ }^{[70]}$ attributed the $120 \mathrm{~cm}^{-1}$ peak to cylindrical graphene walls, but it was not possible to confirm their attribution here.

At $700^{\circ} \mathrm{C}$, peaks corresponding to the formation of NiSi were observed, along with weak peaks probably associated with $\mathrm{NiSi}_{2}$. Indeed, we cannot exclude the formation of a disilicide nickel phase, which is less Raman sensitive than the NiSi phase. At growth temperatures of $800^{\circ} \mathrm{C}$ and above, only the $\mathrm{NiSi}_{2}$ Raman broad peaks were detectable at wavenumbers between 227 to $400 \mathrm{~cm}^{-1}$, whereas the intense Raman signal of the NiSi phase decreased, which may be consistent with the transformation of the $\mathrm{NiSi}$ phase into the $\mathrm{NiSi}_{2}$ phase at the highest temperatures (all Raman spectra were acquired with the same integration time). No similar phases were observed when the graphene was grown on the $\mathrm{SiO}_{2}$ substrate, whatever the temperature (see Supplementary S5). The presence of nickel silicide phases is certainly responsible for the differences in the evolution of the Raman responses between the $\operatorname{Si}(100)$ and $\mathrm{SiO}_{2}$ substrates, as high19ghted in 2PPe follow $399 \mathrm{~g}$ sectiơn? $\quad 500$

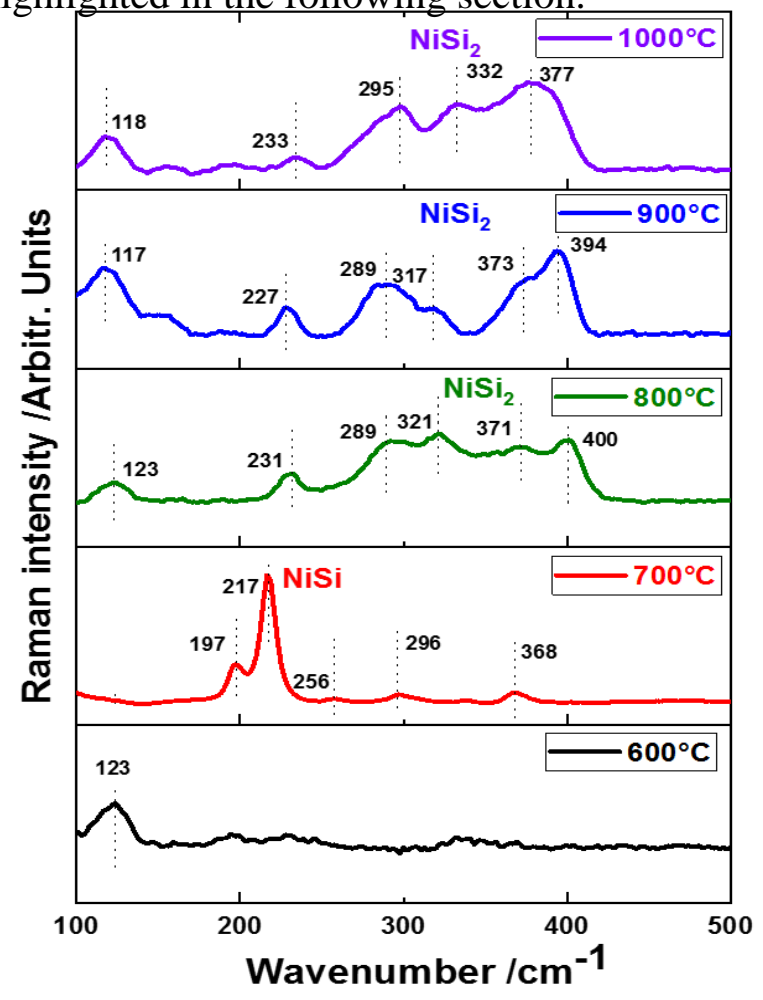


Fig. 5: Raman spectra at $633 \mathrm{~nm}$ for as-grown graphene on $\mathrm{Si}(100)$ with various growth temperatures from 600 to $1000^{\circ} \mathrm{C}$. See text for peak assignments.

\section{Discussion}

\subsection{Effect of the substrate on the graphene film nano-architecture}

High quality few layer graphene is expected to exhibit low $\mathrm{I}_{\mathrm{D}} / \mathrm{I}_{\mathrm{G}}$ and high $\mathrm{I}_{2 \mathrm{D}} / \mathrm{I}_{\mathrm{G}}$ ratios. From the Raman mapping of $\mathrm{I}_{\mathrm{D}} / \mathrm{I}_{\mathrm{G}}$ and $\mathrm{I}_{2 \mathrm{D}} / \mathrm{I}_{\mathrm{G}}$ ratios, it appears that, for each substrate, graphene films with the lowest defects content and number of layers were G-Si-600 and G-SiO $2-1000$. The G-Si-600 film exhibited $\mathrm{I}_{\mathrm{D}} / \mathrm{I}_{\mathrm{G}}$ and $\mathrm{I}_{2 \mathrm{D}} / \mathrm{I}_{\mathrm{G}}$ ratios of 0.297 and 0.438 respectively, whereas the $\mathrm{G}_{-} \mathrm{SiO}_{2}-1000$ film exhibited $\mathrm{I}_{\mathrm{D}} / \mathrm{I}_{\mathrm{G}}$ and $\mathrm{I}_{2 \mathrm{D}} / \mathrm{I}_{\mathrm{G}}$ ratios of 0.140 and 0.721 respectively. In order to evaluate the dominant number of layers on the surface of the two samples compared with the literature, a statistical analysis of the number of graphene layers was performed by combining the $\mathrm{I}_{2 \mathrm{D}} / \mathrm{I}_{\mathrm{G}}$ and FWHM(2D) values deduced from the 400 spectra recorded on each sample. This analysis quantified the distribution of the $\mathrm{I}_{2 \mathrm{D}} / \mathrm{I}_{\mathrm{G}}$ and $\mathrm{FWHM}(2 \mathrm{D})$ values between their minimum and maximum values for each graphene film. As can be seen in Fig. 6, $I_{2 D} / I_{G}$ varied from 0.40 to 0.46 and FWHM(2D) varied from 107 to $114 \mathrm{~cm}^{-1}$ in the G-Si-600 sample, whereas $\mathrm{I}_{2 \mathrm{D}} / \mathrm{I}_{\mathrm{G}}$ varied from 0.40 to 1.10 and $\mathrm{FWHM}(2 \mathrm{D})$ varied from 20 to $90 \mathrm{~cm}^{-1}$ in the G-SiO $2-1000$ sample. Based on Table 1, which correlates $I_{2 D} / I_{G}$ and $F W H M(2 D)$ with the number of layers in the samples from the 50 references in the literature, multilayered $(>5)$ graphene is present on $100 \%$ of the G-Si-600 samples. In the $\mathrm{G}_{-} \mathrm{SiO}_{2}-1000$ sample, $90 \%$ of the spectra present an $\mathrm{I}_{2 \mathrm{D}} / \mathrm{I}_{\mathrm{G}}$ ranging from 0.65 to 1.10 , and a $\mathrm{FWHM}(2 \mathrm{D})$ ranging from 50 to $80 \mathrm{~cm}^{-1}$. The combination of both $\mathrm{I}_{2 \mathrm{D}} / \mathrm{I}_{\mathrm{G}}$ and $\mathrm{FWHM}(2 \mathrm{D})$ indicates a predominant formation of 2-3 graphene layers on the $\mathrm{SiO}_{2}$ substrate. Therefore, it can be concluded that the G-Si-600 sample has homogeneous architecture comprised of $100 \%$ of multilayered graphene, while the $\mathrm{G}_{-} \mathrm{SiO}_{2}-1000$ sample predominantly exhibits a bi- and trilayer architecture. 


\section{G-Si-600}
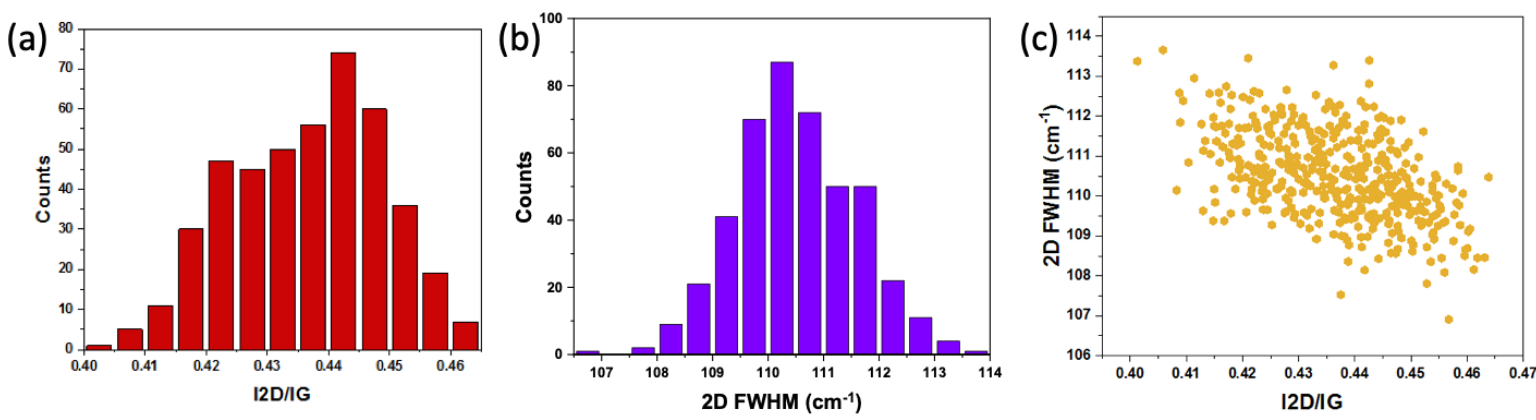

\section{G-SiO -1000}
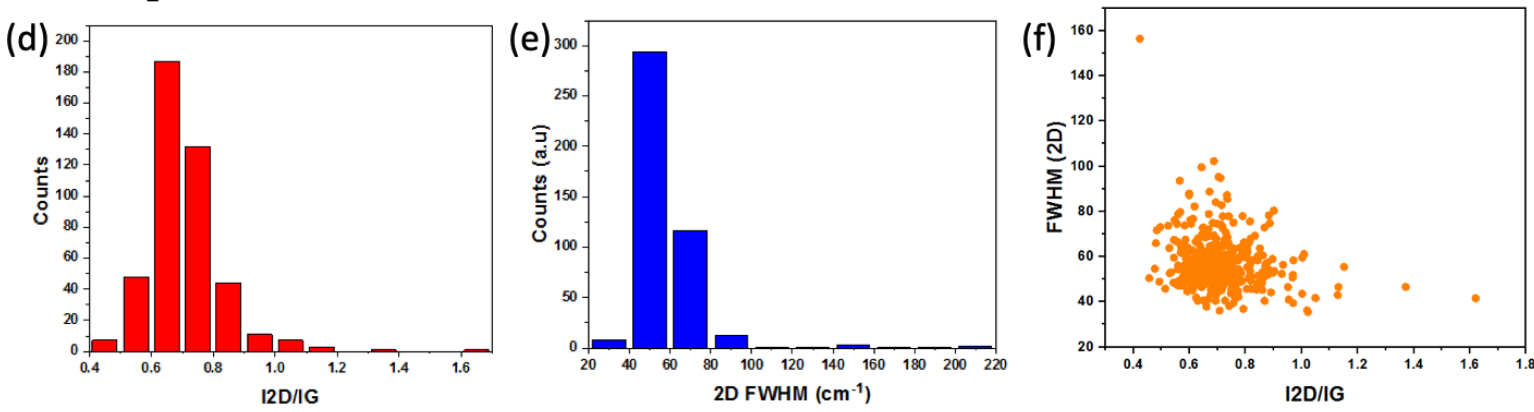

Fig. 6: (a) Histogram of the $I_{2 D} / I_{G}$ intensity ratio measured by Raman spectroscopy of 400 graphene films of the G-Si-600 sample, (b) Histogram of the FWHM(2D) peak measured by Raman spectroscopy for 400 graphene films of the G-Si-600 sample (c) FWHM(2D) peak plotted against the $I_{2 D} / I_{G}$ ratio for G-Si-600. (d) Histogram of the $I_{2 D} / I_{G}$ intensity ratio measured by Raman spectroscopy for 400 graphene films of the G-SiO${ }_{2}-1000$ sample. (b) Histogram of the FWHM(2D) peak measured by Raman spectroscopy for 400 graphene films of the $\mathrm{G}_{-} \mathrm{SiO}_{2}-1000$ sample (c) FWHM(2D) peak plotted against the $\mathrm{I}_{2 \mathrm{D}} / \mathrm{I}_{\mathrm{G}}$ ratio for the $\mathrm{G}-\mathrm{SiO}_{2}-1000$ sample.

\subsection{Differential effect of annealing temperature related to nickel silicide formation}

In addition to Raman mappings of peak ratios and peaks FWHM, the D, G, and 2D peak positions were mapped (see Supplementary S2, S3, S4). Along with the study of $I_{2 D} / I_{G}$ and $\mathrm{I}_{\mathrm{D}} / \mathrm{I}_{\mathrm{G}}$, the evolution of those positions with annealing temperature is shown in Fig. 7 for each substrate. In general, the $\mathrm{G}$ peak position follows the $\mathrm{I}_{\mathrm{D}} / \mathrm{I}_{\mathrm{G}}$ ratio evolution, in good agreement with what was observed on graphite ${ }^{[71,72]}$, with both values increasing with the nanoclustering and the reduction in crystallite size. However, one cannot exclude the impact of compressive stress leading to the $G$ peak upshift, as already reported in other works ${ }^{[73-75]}$. This can be a concern especially in the case of nickel silicide formation leading to a surface texturing of the substrate during post-annealing cooling of the films. It is possible to correlate the increase or decrease in the $2 \mathrm{D}$ peak position with an opposite trend of the $\mathrm{I}_{2 \mathrm{D}} / \mathrm{I}_{\mathrm{G}}$ ratio. This is to be 
expected when referring the literature, as the increase in the number of graphene layers upshifts the position of the $2 \mathrm{D}$ peak ${ }^{[74,76]}$. Here, the position of the $\mathrm{D}$ peak appears to behave in the same way as the position of the $G$ peak and the $I_{D} / I_{G}$ ratio, although it shifts almost twice as far as the $\mathrm{G}$ peak. Relatively few opinions have been expressed in the literature about the position of the D peak, but we suggest that the nanoclustering effects leading to the $G$ peak upshift might produce the same outcome for the D peak.

When considering the $\mathrm{SiO}_{2}$ substrate, increasing the annealing temperature has beneficial effects on the graphene quality. An increase in $\mathrm{I}_{2 \mathrm{D}} / \mathrm{I}_{\mathrm{G}}$, a decrease of $\mathrm{I}_{\mathrm{D}} / \mathrm{I}_{\mathrm{G}}$ and a decrease in the positions of the $\mathrm{D}, \mathrm{G}$, and $2 \mathrm{D}$ peaks indicate that the produced graphene has fewer layers (between 2 and 3) and fewer defects (higher homogeneity). Even though the process of graphene generation using a metal catalyst has not yet been fully elucidated, it appears that the phenomenon is enhanced when the annealing temperature is increased.

This is not the case when graphene is grown on $\mathrm{Si}$ substrate. The impact of temperature appears to be negligible, or at least comparable with what happens on $\mathrm{SiO}_{2}$ up to $800^{\circ} \mathrm{C}$. However, temperatures of $900^{\circ} \mathrm{C}$ and $1000^{\circ} \mathrm{C}$ are clearly detrimental to graphene quality, with $\mathrm{I}_{2 \mathrm{D}} / \mathrm{I}_{\mathrm{G}}$ decreasing and the other parameters increasing $\left(\mathrm{I}_{\mathrm{D}} / \mathrm{I}_{\mathrm{G}}, \mathrm{D}, \mathrm{G}\right.$, and $2 \mathrm{D}$ positions $)$. This means that in this case, the resulting material is a so-called multilayer graphene of a more defective nature. And, as can be seen in Fig. 7, these detrimental effects arise precisely when the most distinctive features of $\mathrm{NiSi}_{2}$ are present in the Raman signature of the films.

It therefore appears that a high annealing temperature is beneficial for the quality of graphene grown using a nickel catalyst, except when the nickel reacts with the substrate. Indeed, the results for $\mathrm{SiO}_{2}$ produced at high temperatures appear to originate in the optimal interaction of the a-C films with its $\mathrm{Ni}$ catalyst. It appears that when nickel silicides grow on the surface of Si substrates, less catalyst is available to produce graphene during annealing. If one considers that the $\mathrm{Ni}$ is consumed during graphene growth, increasing the temperature optimizes the consumption in the case of $\mathrm{SiO}_{2}$, but not in the case of $\mathrm{Si}$, as part of the $\mathrm{Ni}$ is consumed to produce nickel silicide. The formation of such nickel silicide phases reduces the proportion of the metallic nickel phase in which carbon may diffuse towards surface segregation of graphene. So, with $\mathrm{Si}(100)$, a higher proportion of carbon segregates at the surface, compared to what is observed with $\mathrm{SiO}_{2}$ with no nickel silicide phase formation. Such a difference may explain why, with $\mathrm{Si}(100)$, the graphene film is thicker and multilayered, whereas with $\mathrm{SiO}_{2}$ it is thinner with only 2-3 layers. 
It has previously been suggested that the more defective nature of graphene samples grown on silicon using nickel as a catalyst is due to the nano-roughness induced by the formation of nickel silicide. The present work reveals that more complex phenomena may be involved here, in particular, the quantity of nickel available for both graphene growth and nickel silicide formation appears to be critical for the production of few-layer graphene.

(a) Graphene on $\mathrm{Si}(100)$

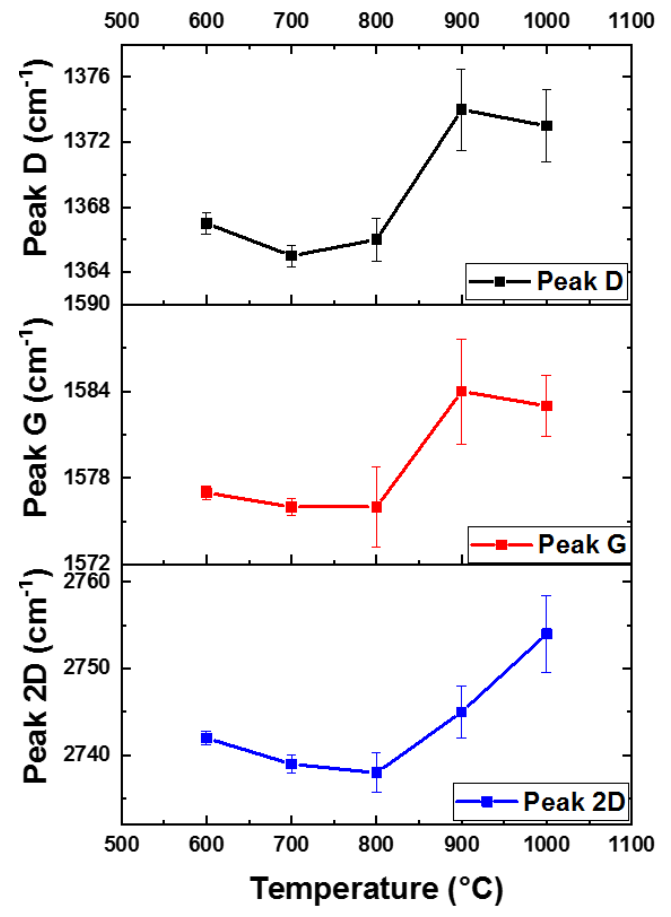

(b) Graphene on $\mathrm{SiO}_{2}$

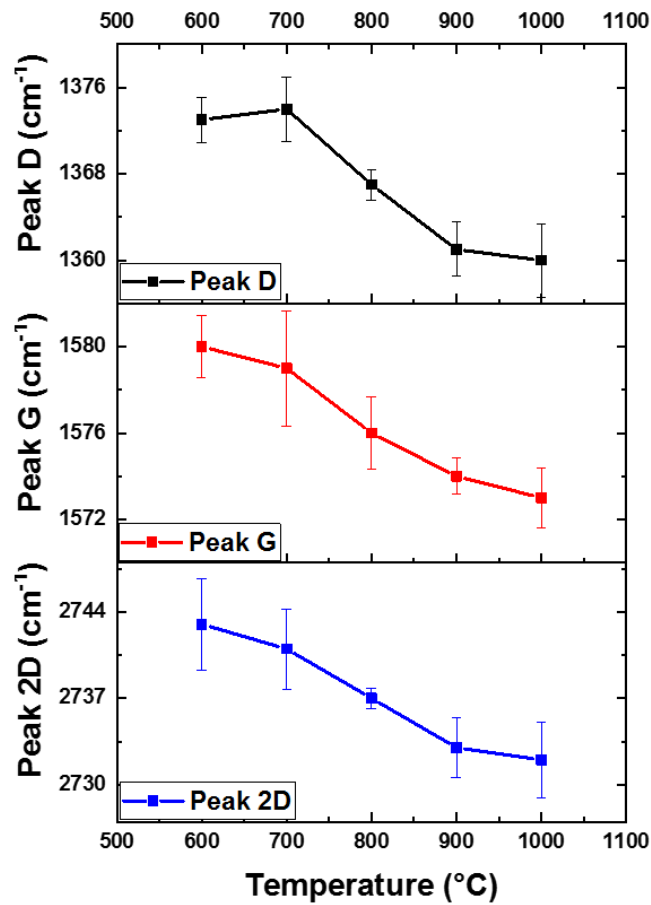

Fig. 7: D, G, and 2D peak positions depending on growth temperature for graphene grown on (a) $\mathrm{Si}(100)$, (b) on $\mathrm{SiO}_{2}$.

\section{Conclusions}

In this paper, we report comparative Raman analysis of the graphene films prepared on $\mathrm{Si}(100)$ and $\mathrm{SiO}_{2}$ substrates by combining high-vacuum pulsed laser deposition and rapid thermal annealing in low vacuum at growth temperatures ranging from 600 to $1000^{\circ} \mathrm{C}$, in the presence of a Ni catalyst layer. The objective was to compare the nature of the graphene films grown from a similar amorphous carbon film, in similar thermal conditions but on two different substrates. The main conclusions are the following: 
- A review of 50 literature references showed that the $\mathrm{I}_{2 \mathrm{D}} / \mathrm{I}_{\mathrm{G}}$ ratio and the FWHM of the 2D peak constitute Raman fingerprints that can be used to differentiate graphene nanoarchitectures with a number of layers ranging between 1 and 5, but with some uncertainties due to only partial recovery of these fingerprint ranges from one reference to another.

- The two different $\mathrm{Si}(100)$ and $\mathrm{SiO}_{2}$ substrates, with an identical a-C/Ni top layer, are covered by a quite similar graphene film when growth occurs at $600^{\circ} \mathrm{C}$. Growth at temperatures ranging from 700 to $1000^{\circ} \mathrm{C}$ induces very different behavior of the Raman signal, highlighting a significant effect of the substrate on the nanoarchitecture of the graphene film. The formation of nickel silicide phases between 700 and $1000^{\circ} \mathrm{C}$, particularly above $900^{\circ} \mathrm{C}$, is responsible for this difference.

- On the $\mathrm{Si}(100)$ substrate, increasing growth temperature leads to the synthesis of defective multilayered graphene film, with a decrease in the crystallite size with temperature.

- On the $\mathrm{SiO}_{2}$ substrate, the increase in growth temperature results in a less defective graphene film, mainly comprised of 2-3 layers with larger crystallites.

- Higher annealing temperature benefits graphene growth when $\mathrm{Ni}$ is used as a catalyst on $\mathrm{SiO}_{2}$, and this appears to be due to optimal consumption of the catalyst during the synthesis. This effect is cancelled during growth on $\mathrm{Si}$, as the formation of nickel silicide, which increases at higher temperatures, limits the amount of catalyst available for graphene synthesis.

These findings underline the fact that, beyond parameters such as annealing temperature and synthesis conditions, the choice of an appropriate substrate for growth of graphene from a solid source using a metal catalyst is a useful tool to control the properties of graphene, including the number of defects and the number of layers.

\section{Acknowledgements}

This work was conducted with the financial support of the Future Program Lyon SaintEtienne (PALSE) in the framework of the LABEX MANUTECH-SISE (ANR-10-LABX0075) from the University of Lyon (ANR-11-IDEX-0007), under the Investissements d'Avenir program managed by the French National Research Agency (French acronym ANR).

\section{References}


[1] R. R. Nair, P. Blake, A. N. Grigorenko, K. S. Novoselov, T. J. Booth, T. Stauber, N. M. R. Peres, A. K. Geim, Science 2008, 320, 1308.

[2] C. Lee, X. Wei, J. W. Kysar, J. Hone, Science 2008, 321, 385.

[3] A. A. Balandin, S. Ghosh, W. Bao, I. Calizo, D. Teweldebrhan, F. Miao, C. N. Lau, Nano Lett. 2008, 8, 902.

[4] R. S. Edwards, K. S. Coleman, Acc. Chem. Res. 2013, 46, 23.

[5] K. I. Bolotin, K. J. Sikes, Z. Jiang, M. Klima, G. Fudenberg, J. Hone, P. Kim, H. L. Stormer, Solid State Commun. 2008, 146, 351.

[6] D. L. Nika, A. A. Balandin, Rep. Prog. Phys. 2017, 80, 036502.

[7] H. Malekpour, A. A. Balandin, J. Raman Spectrosc. 2018, 49, 106.

[8] K. S. Novoselov, V. I. Fal'ko, L. Colombo, P. R. Gellert, M. G. Schwab, K. Kim, Nature 2012, 490, 192.

[9] A. K. Geim, K. S. Novoselov, Nat. Mater. 2007, 6, 183.

[10] Y. D. Kim, M.-H. Bae, J.-T. Seo, Y. S. Kim, H. Kim, J. H. Lee, J. R. Ahn, S. W. Lee, S.H. Chun, Y. D. Park, ACS Nano 2013, 7, 5850.

[11] F. Bonaccorso, Z. Sun, T. Hasan, A. C. Ferrari, Nat. Photonics 2010, 4, 611.

[12] T. Kuila, S. Bose, P. Khanra, A. K. Mishra, N. H. Kim, J. H. Lee, Biosens. Bioelectron. 2011, 26, 4637.

[13] J. Plutnar, M. Pumera, Z. Sofer, J. Mater. Chem. C 2018, 6, 6082.

[14] C. K. Chua, M. Pumera, Chem Soc Rev 2014, 43, 291.

[15] X. Ye, Q. Zhou, C. Jia, Z. Tang, Y. Zhu, Z. Wan, Carbon 2017, 114, 424.

[16] F. Liang, T. Watanabe, K. Hayashi, Y. Yao, W. Ma, Bin Yang, Y. Dai, Mater. Lett. 2017, 187, 32.

[17] M. Yi, Z. Shen, J. Mater. Chem. A 2015, 3, 11700.

[18] F. Zarotti, B. Gupta, F. Iacopi, A. Sgarlata, M. Tomellini, N. Motta, Carbon 2016, 98, 307.

[19] C. Faugeras, A. Nerrière, M. Potemski, A. Mahmood, E. Dujardin, C. Berger, W. A. de Heer, Appl. Phys. Lett. 2008, 92, 011914.

[20] J. H. Chu, J. Kwak, T.-Y. Kwon, S.-D. Park, H. Go, S. Y. Kim, K. Park, S. Kang, S.-Y. Kwon, ACS Appl. Mater. Interfaces 2012, 4, 1777.

[21] C. Maddi, F. Bourquard, V. Barnier, J. Avila, M.-C. Asensio, T. Tite, C. Donnet, F. Garrelie, Sci. Rep. 2018, 8, 3247.

[22] B. Shen, J. Ding, X. Yan, W. Feng, J. Li, Q. Xue, Appl. Surf. Sci. 2012, 258, 4523.

[23] S. An, G.-H. Lee, S. W. Jang, S. Hwang, S. H. Lim, S. Han, Carbon 2016, 109, 154.

[24] P. Fortgang, T. Tite, V. Barnier, N. Zehani, C. Maddi, F. Lagarde, A.-S. Loir, N. Jaffrezic-Renault, C. Donnet, F. Garrelie, C. Chaix, ACS Appl. Mater. Interfaces 2016, 8, 1424.

[25] M. Miyoshi, Y. Arima, T. Kubo, T. Egawa, Appl. Phys. Lett. 2017, 110, 013103.

[26] Y. Bleu, F. Bourquard, T. Tite, A.-S. Loir, C. Maddi, C. Donnet, F. Garrelie, Front. Chem. 2018, 6, 00572.

[27] Y. Hao, L. Wang, Y. Liu, H. Chen, X. Wang, C. Tan, S. Nie, J. W. Suk, T. Jiang, T. Liang, J. Xiao, W. Ye, C. R. Dean, B. I. Yakobson, K. F. McCarty, P. Kim, J. Hone, L. Colombo, R. S. Ruoff, Nat. Nanotechnol. 2016, 11, 426.

[28] K. Shen, H. Sun, J. Hu, J. Hu, Z. Liang, H. Li, Z. Zhu, Y. Huang, L. Kong, Y. Wang, Z. Jiang, H. Huang, J. W. Wells, F. Song, J. Phys. Chem. C 2018, 122, 21484.

[29] M. H. Oliveira, T. Schumann, F. Fromm, R. Koch, M. Ostler, M. Ramsteiner, T. Seyller, J. M. J. Lopes, H. Riechert, Carbon 2013, 52, 83.

[30] S. P. Cooil, F. Song, G. T. Williams, O. R. Roberts, D. P. Langstaff, B. Jørgensen, K. Høydalsvik, D. W. Breiby, E. Wahlström, D. A. Evans, J. W. Wells, Carbon 2012, 50, 5099. 
[31] G. K. Hemani, W. G. Vandenberghe, B. Brennan, Y. J. Chabal, A. V. Walker, R. M. Wallace, M. Quevedo-Lopez, M. V. Fischetti, Appl. Phys. Lett. 2013, 103, 134102.

[32] A. T. T. Koh, Y. M. Foong, D. H. C. Chua, Diam. Relat. Mater. 2012, 25, 98.

[33] T. Tite, V. Barnier, C. Donnet, A. Loir, S. Reynaud, J. Michalon, F. Vocanson, F. Garrelie, Thin Solid Films 2016, 604, 74.

[34] M. Qian, Y. S. Zhou, Y. Gao, J. B. Park, T. Feng, S. M. Huang, Z. Sun, L. Jiang, Y. F. Lu, Appl. Phys. Lett. 2011, 98, 173108.

[35] I. Kumar, A. Khare, Appl. Surf. Sci. 2014, 317, 1004.

[36] P. Ren, E. Pu, D. Liu, Y. Wang, B. Xiang, X. Ren, Mater. Lett. 2017, 204, 65.

[37] A. E. M. Abd Elhamid, M. A. Hafez, A. M. Aboulfotouh, I. M. Azzouz, J. Appl. Phys. 2017, 121, 025303.

[38] R. S. Weatherup, B. C. Bayer, R. Blume, C. Baehtz, P. R. Kidambi, M. Fouquet, C. T. Wirth, R. Schlögl, S. Hofmann, ChemPhysChem 2012, 13, 2544.

[39] A. C. Ferrari, J. C. Meyer, V. Scardaci, C. Casiraghi, M. Lazzeri, F. Mauri, S. Piscanec, D. Jiang, K. S. Novoselov, S. Roth, A. K. Geim, Phys. Rev. Lett. 2006, 97, 187401.

[40] L. M. Malard, M. A. Pimenta, G. Dresselhaus, M. S. Dresselhaus, Phys. Rep. 2009, 473, 51.

[41] A. C. Ferrari, Solid State Commun. 2007, 143, 47.

[42] A. Das, S. Pisana, B. Chakraborty, S. Piscanec, S. K. Saha, U. V. Waghmare, K. S. Novoselov, H. R. Krishnamurthy, A. K. Geim, A. C. Ferrari, A. K. Sood, Nat. Nanotechnol. 2008, 3, 210.

[43] D. Graf, F. Molitor, K. Ensslin, C. Stampfer, A. Jungen, C. Hierold, L. Wirtz, Eur. Phys. J. Spec. Top. 2007, 148, 171.

[44] S. Chen, Q. Li, Q. Zhang, Y. Qu, H. Ji, R. S. Ruoff, W. Cai, Nanotechnology 2012, 23, 365701.

[45] A. C. Ferrari, D. M. Basko, Nat. Nanotechnol. 2013, 8, 235.

[46] J.-B. Wu, X. Zhang, M. Ijäs, W.-P. Han, X.-F. Qiao, X.-L. Li, D.-S. Jiang, A. C. Ferrari, P.-H. Tan, Nat. Commun. 2014, 5, 5309.

[47] M. S. Dresselhaus, A. Jorio, A. G. S. Filho, R. Saito, Philos. Trans. R. Soc. Lond. Math. Phys. Eng. Sci. 2010, 368, 5355.

[48] D. Teweldebrhan, A. A. Balandin, Appl. Phys. Lett. 2009, 94, 013101.

[49] H. Malekpour, P. Ramnani, S. Srinivasan, G. Balasubramanian, D. L. Nika, A. Mulchandani, R. K. Lake, A. A. Balandin, Nanoscale 2016, 8, 14608.

[50] S. Amini, J. Garay, G. Liu, A. A. Balandin, R. Abbaschian, J. Appl. Phys. 2010, 108, 094321.

[51] I. Calizo, W. Bao, F. Miao, C. N. Lau, A. A. Balandin, Appl. Phys. Lett. 2007, 91, 201904.

[52] I. Calizo, S. Ghosh, W. Bao, F. Miao, C. Ning Lau, A. A. Balandin, Solid State Commun. 2009, 149, 1132.

[53] G. Amato, F. Beccaria, E. Landini, E. Vittone, J. Raman Spectrosc. 2019, 50, 499.

[54] M. Bayle, N. Reckinger, A. Felten, P. Landois, O. Lancry, B. Dutertre, J.-F. Colomer, A.-A. Zahab, L. Henrard, J.-L. Sauvajol, M. Paillet, J. Raman Spectrosc. 2018, 49, 36.

[55] E. Cazzanelli, O. D. Luca, D. Vuono, A. Policicchio, M. Castriota, G. Desiderio, M. P. D. Santo, A. Aloise, A. Fasanella, T. Rugiero, R. G. Agostino, J. Raman Spectrosc. 2018, 49, 1006.

[56] M.-L. Lin, T. Chen, W. Lu, Q.-H. Tan, P. Zhao, H.-T. Wang, Y. Xu, P.-H. Tan, J. Raman Spectrosc. 2018, 49, 46.

[57] V. N. Popov, J. Raman Spectrosc. 2018, 49, 31.

[58] J. E. Weis, J. Vejpravova, T. Verhagen, Z. Melnikova, S. Costa, M. Kalbac, J. Raman Spectrosc. 2018, 49, 168. 
[59] L. G. Cançado, K. Takai, T. Enoki, M. Endo, Y. A. Kim, H. Mizusaki, A. Jorio, L. N. Coelho, R. Magalhães-Paniago, M. A. Pimenta, Appl. Phys. Lett. 2006, 88, 163106.

[60] A. C. Ferrari, J. Robertson, Philos. Trans. R. Soc. Lond. Ser. Math. Phys. Eng. Sci.

[61] M. W. Iqbal, A. K. Singh, M. Z. Iqbal, J. Eom, J. Phys. Condens. Matter 2012, 24, 335301.

[62] F. Bourquard, Y. Bleu, A.-S. Loir, B. Caja-Munoz, J. Avila, M.-C. Asensio, G. Raimondi, M. Shokouhi, I. Rassas, C. Farre, C. Chaix, V. Barnier, N. Jaffrezic-Renault, F. Garrelie, C. Donnet, Materials 2019, 12, 666.

[63] E. Escobedo-Cousin, K. Vassilevski, T. Hopf, N. Wright, A. O’Neill, A. Horsfall, J. Goss, P. Cumpson, J. Appl. Phys. 2013, 113, 114309.

[64] Z.-Y. Juang, C.-Y. Wu, C.-W. Lo, W.-Y. Chen, C.-F. Huang, J.-C. Hwang, F.-R. Chen, K.-C. Leou, C.-H. Tsai, Carbon 2009, 47, 2026.

[65] S. Cichoň, P. Macháč, B. Barda, V. Machovič, P. Slepička, Thin Solid Films 2012, 520, 4378.

[66] F. F. Zhao, J. Z. Zheng, Z. X. Shen, T. Osipowicz, W. Z. Gao, L. H. Chan, Microelectron. Eng. 2004, 71, 104.

[67] P. S. Lee, Electrochem. Solid-State Lett. 1999, 3, 153.

[68] S. K. Donthu, D. Z. Chi, S. Tripathy, A. S. W. Wong, S. J. Chua, Appl. Phys. A 2004, $79,637$.

[69] M. Bhaskaran, S. Sriram, T. S. Perova, V. Ermakov, G. J. Thorogood, K. T. Short, A. S. Holland, Micron 2009, 40, 89.

[70] P. V. Huong, R. Cavagnat, P. M. Ajayan, O. Stephan, Phys. Rev. B 1995, 51, 10048.

[71] A. C. Ferrari, J. Robertson, Phys. Rev. B 2000, 61, 14095.

[72] A. C. Ferrari, J. Robertson, Philos. Trans. R. Soc. Lond. Ser. Math. Phys. Eng. Sci. 2004, $362,2477$.

[73] J. Röhrl, M. Hundhausen, K. V. Emtsev, Th. Seyller, R. Graupner, L. Ley, Appl. Phys. Lett. 2008, 92, 201918.

[74] D. S. Lee, C. Riedl, B. Krauss, K. von Klitzing, U. Starke, J. H. Smet, Nano Lett. 2008, 8,4320 .

[75] Z. H. Ni, H. M. Wang, Y. Ma, J. Kasim, Y. H. Wu, Z. X. Shen, ACS Nano 2008, 2, 1033.

[76] T. A. Nguyen, J.-U. Lee, D. Yoon, H. Cheong, Sci. Rep. 2014, 4, 4630. 